\title{
Deformation and Fracture of a Layered VT6-Based Material under Shock Loading
}

\author{
Natalya Surikova $^{1, \text { a) }}$, Viktor Panin ${ }^{1,2}$, Lyudmila Derevyagina ${ }^{1}$, \\ Ramile Lutfullin ${ }^{3}$, and Aleksandra Sarkeeva ${ }^{3}$ \\ ${ }^{1}$ Institute of Strength Physics and Materials Science SB RAS, Tomsk, 634055, Russia \\ ${ }^{2}$ National Research Tomsk Polytechnic University, Tomsk, 634050, Russia \\ ${ }^{3}$ Institute for Metals Superplasticity Problems RAS, Ufa, 450001, Russia \\ a) Corresponding author: surikova@ispms.tsc.ru
}

\begin{abstract}
In the work, we investigate in detail the mechanisms of plastic deformation, structure transformations and fracture in layered VT6-based material under shock loading.

Keywords: layered material, titanium alloy, shock-bending load test at $20^{\circ} \mathrm{C}$ and $-196^{\circ} \mathrm{C}$, structural-phase decomposition in fracture zones, material fragmentation in sublayers
\end{abstract}

\section{INTRODUCTION}

Ultrafine-grained titanium alloy shave better strength $\left(\sigma_{\mathrm{B}} \sim 1300-1500 \mathrm{MPa}, \sigma_{0.2} \sim 1190 \mathrm{MPa}\right)$ and fatigue characteristics as compared to microcrystalline alloys, but they also have lower plasticity and resistance to shock [1, 2]. Some methods of improving crack toughness are associated with the creation of structural anisotropy in materials which leads to changes in the growth of the main crack and its branching.

This factor is utilized in the creation of layered materials whose structural characteristic feature is the internal surface of the interface $[3,4]$.

This article describes mechanisms of plastic deformation and fracture of a titanium alloy layered material under shock loading.

\section{METHODS OF THE EXPERIMENT}

The layered material was received by pressure welding of thirteen parent sheets of VT6titanium alloy of industrial rolling. Before packing the surfaces of the parent sheets were mechanically polished until the surface roughness of $\mathrm{R}_{\mathrm{a}}=0.4 \mu \mathrm{m}$ was attained. Then the samples were washed in fine acetone.

Welding of the package was done at the temperature of $750{ }^{\circ} \mathrm{C}$ in $2 \cdot 10^{-3} \mathrm{~Pa}$ vacuum. The angle between the rolling directions in the neighboring parent sheets of the package was $90^{\circ}$. The layered samples for the shockbending test were cut into $10 \times 10 \times 15 \mathrm{~mm}^{3}$ pieces as per GOST 9454-78. The configuration of the samples' geometry featured the location of layer separation that "slows down" the crack $[3,4]$. The porosity value in the zone of the solid phase junction $L_{\mathrm{p}}$ was 0.32 [4]. Shock-bending tests were conducted at room temperature and at the temperature of liquid nitrogen, using the Tinius Olsen IT542M pendulum impact testing machine, and the diagram of the impact load was recorded. The impact value of the layered material was from 7 to 10 times better than that of the all-in-one VT6 alloy [4]. The studies of the microstructure and phase material composition were conducted with the help of the JEM-2100electrontransmission microscope (the accelerating voltage of $200 \mathrm{kV}$ ) and the DRON-7Xray unit. The analysis of the destructed surfaces was conducted with the help of the Philips SEM 515 focused-beam scanning microscope.

International Conference on Physical Mesomechanics of Multilevel Systems 2014

AIP Conf. Proc. 1623, 623-626 (2014); doi: 10.1063/1.4899022

(C) 2014 AIP Publishing LLC 978-0-7354-1260-6/\$30.00 


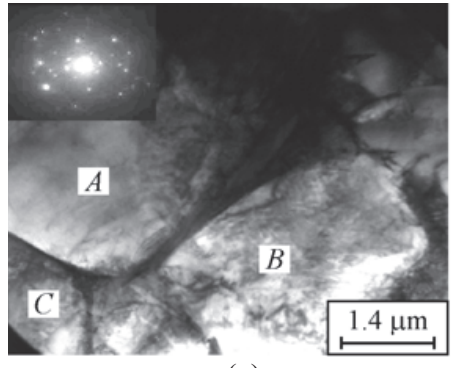

(a)

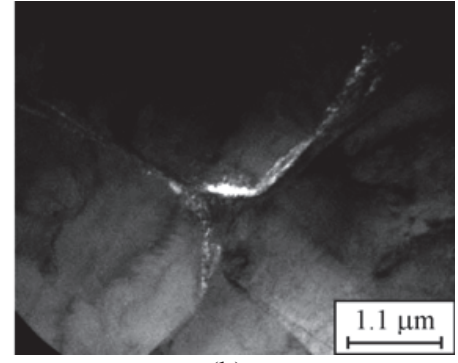

(b)

FIGURE 1. Structure of the titanium alloy parent sheet after welding, longitudinal section: (a) bright-field image, letters $A, B$ and $C$ denote separate grains, a diffraction of the joint of three grains; (b) dark-field image in the reflex of a $110 \beta$-phase type

\section{RESULTS OF THE RESEARCH AND THEIR DISCUSSION}

The study of thin foils with the help of the electronic microscope showed that the microstructure of VT6 alloy sheets after assembly welding comprised $\alpha$-phase grains with the average size of $d \sim 3.5 \mu \mathrm{m}$ surrounded by the $\beta$-phase intercrystallite interlayer. The amount of the remaining unstable $\beta$-phase in the alloy after welding was $\sim 7 \%$ of the whole volume of the material.

Shock-bending deformation showed that the layered material can be considered as a multileveled hierarchically organized system, whose impact toughness is determined by the micromechanisms of titanium alloy sheets deformation as well as by the micromechanisms of the material deformation in the planar subsystem of a solid-phase sheets joint (Fig. 2). In Fig. 2 we can see, that the toughness of the workpiece, which was deformed at room temperature $\left(\mathrm{KCV} \sim 3.2 \mathrm{MJ} / \mathrm{m}^{2}\right)$, is much higher than the toughness of the sample deformed at $-196^{\circ} \mathrm{C}(\mathrm{KCV} \sim$ $2.09 \mathrm{MJ} / \mathrm{m}^{2}$ ). It happens because in alow-temperature impact, the workpiece consisting of thirteen parent sheets flakes into five smaller assemblies while at the temperature of $20^{\circ} \mathrm{C}$, into three assemblies only. And at $-196^{\circ} \mathrm{C}$ four smaller assemblies of sheets are destructed according to the scheme of normal fracturing and only one is destructed viscously. At $20^{\circ} \mathrm{C}$ only two smaller assemblies follow the scheme of normal fracturing and the third smaller assembly is deformed plastically by bending without destruction.

Layering of the assembly is accompanied by a decrease in the load at the descending part of the load curve (Fig. 3) which is responsible for crack expansion. It stops the main crack and forces it to appear again and again on the new surfaces of the interface. The load decreases with the separation of every small assembly. Small assemblies undergo plastic rebending, unloading and separation from the neighboring assembly. This kind of load curve indicates a very high speed of destruction of the assemblies and that of the hard-phase junction zone as well as a major localization of plastic deformation with the appearance of adiabatic shift bands [5,6]. It influences the micromechanisms of the destruction of layers neighboring to the crack.

To study the influence of the shock load on the structure an don the destruction of layered titanium material, two types of foils were cut out of the deformed specimens: one parallel to the surfaces of the destruction of small assemblies and one parallel to the surface of the hard-phase junction in the zone of parent sheets' flaking (the surface of flaking) (Fig. 2).

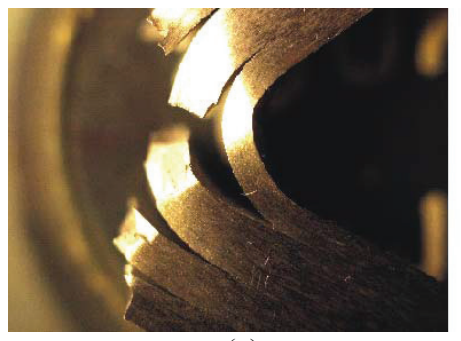

(a)

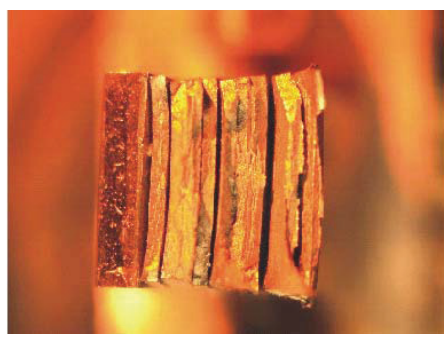

(b)

FIGURE 2. Image of work pieces of layered alloy VT6 deformed by shock impact at $20^{\circ} \mathrm{C}$ (a) and $-196^{\circ} \mathrm{C}$ (b) 


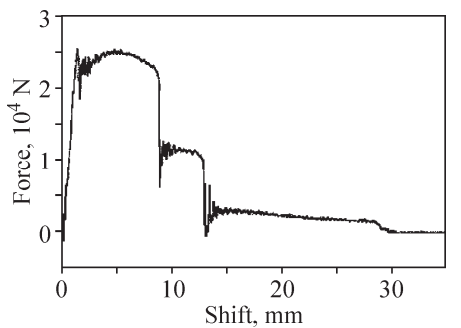

FIGURE 3. Diagram of the shock load of the layered work piece at room temperature. The space under the load curve corresponds to the complete operation of destruction $A=A_{\mathrm{b}}+A_{\mathrm{e}}$, where $A_{\mathrm{b}}$ is the crack birth, equal to the area under the rising part of shock load curve, $A_{\mathrm{e}}$ is the work of the crack expansion, which is equal to the area under the descending part of the curve
Figure 4 shows the deformed structure in the zones of assembly destructions at room temperature. It is obvious (Fig. 4(a)) that a high density of dislocation can be seen in the grain of the $\alpha$-phase $(A)-\rho \sim 3 \times 10^{10} \mathrm{~cm}^{-2}$, as well as a continuous and discrete misorientation of crystallographic planes. Low-angle subboundaries with the misorientation angle of less than $\sim 1^{\circ}$ can be seen very well in reflex $011_{\alpha}$ (shown with white arrows). In the $\beta$ phase intercrystallite interlayers some dislocational shift can be seen, though the strength of the $\beta$-phase is higher (700-1200 MPa) than that of the $\alpha$-phase (560-700 MPa) $[7,8]$. The difference between the strength characteristics of the $\alpha$ - and $\beta$-phases results in the accumulation of dislocations in the interphase $\alpha / \beta$-boundary, which creates the fields of high inner strains. The level of these strains can be determined by the dark-field method, suggested in [9].

Figures $4(\mathrm{~b}, \mathrm{c})$ show the dark-field of grain in the $\alpha$-phase in reflex $1 \overline{1} 1_{\alpha}$ at different angles of inclination $\alpha$ of the foil in the goniometer. In the field out lined by the white circle, the contour of extinction that corresponds to the reflecting planes of $(1 \overline{1} 1)$ the $\alpha$-phase reserves its displacement at the inclination of foils at the angles of $16^{\circ}-$ $20.54^{\circ}$. Thus [9], in this zone the curvature of the reflecting crystallographic planes is $\chi_{31} \approx 45^{\circ} / \mu \mathrm{m}$, and the inside strains are $\sigma_{\text {inside }} \approx G / 15$ ( $G$ is the shift module), which is similar to the theoretical density of the material. This strain can easily initiate a shift in the neighboring volume of the $\beta$-phase or along the surface of the phases' separation as well as an initiate a crack birth. The presence of high-strength $\beta$-phase $\alpha$-Ti grains along the periphery leads to the dispersion of non-linear waves of destruction and to the formation of dynamic rotations on the surface of destruction. The image obtained with the help of the electron microscope often shows small $(\sim 20 \mathrm{~nm})$ particles of $\alpha_{2}$-phase (phase $\mathrm{Ti}_{3} \mathrm{Al}$ ) near the contours of extinction, which indicates the decay of the $\alpha$-solid solution at room temperatures. The peculiarity of the plastic deformation of layered material at the temperature of $-196^{\circ} \mathrm{C}$ (Fig. 5), is that lowtemperature and shock-bending deformation initiates the $\beta \rightarrow \alpha$ phase transformation and increases the decay of $\alpha$ phase in the sheets of the VT6 alloy. It is evidenced by the absence of an intercrystallite interlayer of $\beta$-phase around $\alpha$-grains and by an increase in the number of particles of the $\mathrm{Ti}_{3} \mathrm{Al}$ phase down to $\sim 50-150 \mathrm{~nm}$. In the zones of the material's pre-fracture, the decay of $\alpha$-solid solution is accompanied by the formation of martensitic $\alpha^{\prime}$ and $\alpha^{\prime \prime}$ phases and the appearance of sheet-like precipitates of the intermetallic $\mathrm{TiAl}_{3}$ phase. Martensitic deformation is probably facilitated by the structural instability of the crystal hexagonal close-packed lattice (HPU) of the $\alpha$-phase. The subtraction of small particles of $\mathrm{Ti}_{3} \mathrm{Al}$ and $\mathrm{TiAl}_{3}$ aluminides strengthens the material of the parent sheets effectively, and bigger particles can become the concentrators of strains and lead to the destruction at the temperature of $-196^{\circ} \mathrm{C}$.

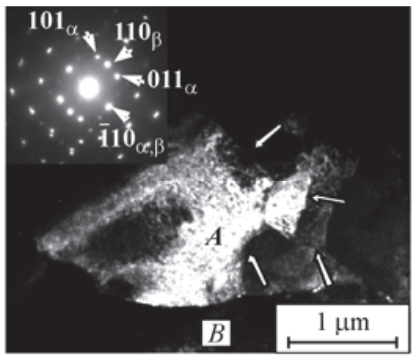

(a)

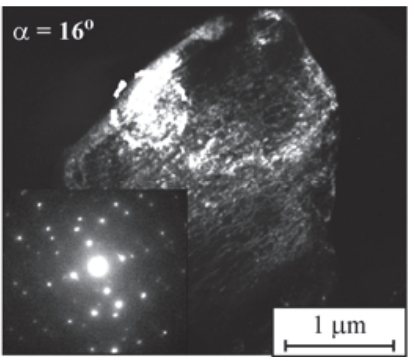

(b)

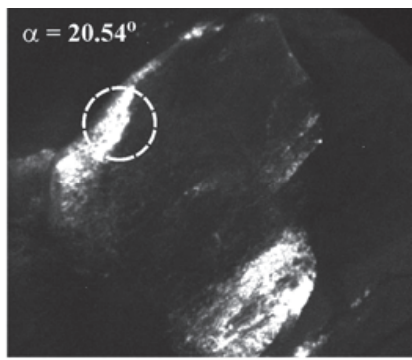

(c)

FIGURE 4. Deformation structure in the destruction zone of a VT6 titanium alloy sheet after shock-bending at $T=20^{\circ} \mathrm{C}$ : (a) small-angular substructure in $\alpha$-phase grain $(A)$, dark-field image in $011_{\alpha}$ reflex, $B$ is a $\beta$-phase intercrystalline layer, at the microdiffraction, the two zones are in a reflecting position: $[11 \overline{1}]_{\alpha}$ zone of $\alpha$-phase and $[001]_{\beta}$ zone of $\beta$-phase;

(b) and (c) are dark field images in the reflex of $\alpha$-phase at different angles $\alpha$ of inclination of the foil in the goniometer of the electronic microscope 


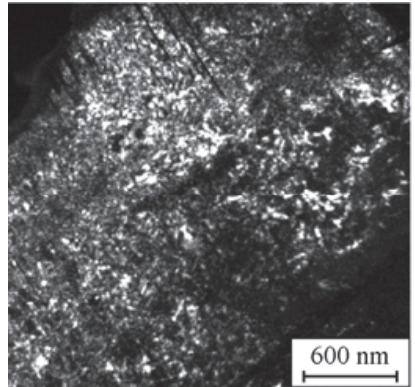

(a)

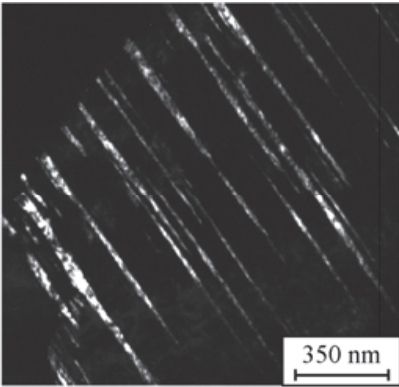

(b)

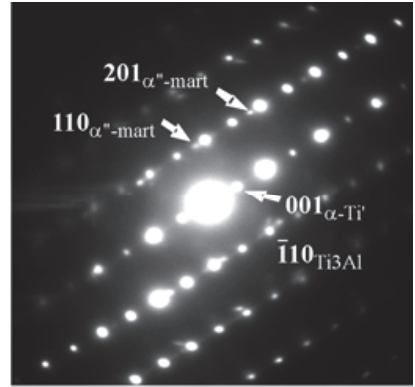

(c)

FIGURE 5. Decay of the sheets material with the subtraction of $\alpha_{2}$-phase particles (a) and the formation of orthorhombic $\alpha^{\prime \prime}$-martensite $(\mathrm{b}, \mathrm{c})$ in the zone of destruction at $T=-196^{\circ} \mathrm{C}$. (a) is a dark field in the co-reflexes $001_{\alpha-\mathrm{Ti}}$ and $[\overline{1} 10]_{\mathrm{Ti} 3 \mathrm{Al}}$; (b) is a dark field image of plates of $\alpha^{\prime \prime}$-martensite in reflex $110_{\alpha^{\prime \prime} \text {-mart; }}$ (c) is a compound microdiffraction from $\alpha$-phase, $\alpha_{2}$-phase and $\alpha^{\prime \prime}$-martensite, zone $[010]_{\alpha-\mathrm{Ti}},[11 \overline{2}]_{\mathrm{Ti} 3 \mathrm{Al}},[\overline{1} 12]_{\alpha^{\prime \prime} \text {-mart }}$

The most important peculiarity of shock bending deformation is the formation of curvature zones in subsurface volumes of the parent sheets, which can lead to the separation of the assembly. Research with the help of electron microscopes and X-ray equipment has shown that the presence of the fragile oxide layers of $\mathrm{Ti}_{2} \mathrm{O}$ and $\mathrm{TiO}_{2}$, which can be found at the surfaces of VT6 sheets under solid-phase welding lead to layers separation, probably because of the insufficient activation of diffusive processes at $750{ }^{\circ} \mathrm{C}$. Under the surface of the solid-phase junction, the local curvature initiates the intensive fragmentation of $\alpha$-phase grains with the appearance of a subgrain structure of 300$500 \mathrm{~nm}$ in size.

\section{CONCLUSION}

Layered material is a multilayered hierarchically organized system where an important role in the deformation and destruction is played by a planar 2D subsystem of plates (besides the crystalline 3D subsystem of VT6 alloy plates). This 2D subsystem of plates comprises the surfaces of the solid-phase junction. In the crystalline sublayers of destruction surfaces and separation surfaces, the fragmentation of material with a discrete misorientation of mesofragments takes place. Influence of the location of layers separation surfaces which slows down crack propagation depends on the deformation temperature. At $T_{\text {def }}=20^{\circ} \mathrm{C}$ the multilayered sample is separated into three small packages. One of them is deformed plastically without fracturing. At the $T_{\mathrm{def}}=-196^{\circ} \mathrm{C}$ the sample is separated into five small packages which all destruct successively. It is determined by the harsher conditions under load at failure, the low coefficient of crack stopping and, consequently, a lower shock-bending strength of the multilayered samples at $T_{\mathrm{def}}=-196^{\circ} \mathrm{C}$. Failure of the multilayered samples leads to the development of structural-phase decay of the material on the surfaces of destruction with the extraction of $\mathrm{Ti}_{3} \mathrm{Al}$ and $\mathrm{TiAl}_{3}$ particles, the appearance of martensitic phases and the formation of dynamic rotations. Lowering of the deformation temperature leads to the reduction of dynamic rotations and the reduction of the roughness of destruction surfaces. The places of inner strains location in a layered titanic alloy material are the boundaries between the $\alpha$ - and $\beta$-phase, the $\alpha$-phase and the $\mathrm{Ti}_{3} \mathrm{Al}$ phase, as well as the surfaces of solid-phase joint of sheets.

The work was performed with the support of RFBR grant No. 13-01-00403 using the equipment of the "NANOTECH" Common Use Center of ISPMS SB RAS.

\section{REFERENCES}

1. L. R. Saitova, I. P. Semenova, G. I. Raab, and R. Z. Valiev, Deform. Destruct. 3, 31 (2005).

2. S. P. Malyshev, M. A. Murzinova, S. V. Zherebtsov, and G. A. Salishev, Perspect. Mater. 12, 316 (2011).

3. R. V. Hertsberger, Deformation and Mechanics of Destruction of Construction Materials (Metallurgy, Moscow, 1989).

4. A. A. Sarkeeva, A. A. Kruglov, E. M. Borodin, et al., Fiz. Mezomekh. 5(1), 51 (2012).

5. G .A. Stepanov and V. A. Fedorchuk, Probl. Strength 2, 27 (2000).

6. T. W. Wright, The Physics and Mechanics of Adiabatic Shear Bands (Cambridge Univ. Press, 2002).

7. U. Tsvikker, Titanum and its Alloys (Metallurgy, Moscow, 1979).

8. E. V. Collings, Physical Material Science of Titanium Alloys (Metallurgy, Moscow, 1988).

9. A. D. Korotaev, A. N. Tumentsev, and V. F. Suhovarov, Dispersive Strengthening of Heat-Resistant Metals (Nauka, Moscow, 1989). 